\title{
Blue Native Polyacrylamide Gel Electrophoresis: A Powerful Tool in Diagnosis of Oxidative Phosphorylation Defects
}

\author{
RUDY VAN COSTER, JOEL SMET, EDITH GEORGE, LINDA DE MEIRLEIR, SARA SENECA, \\ JOHAN VAN HOVE, GUILLAUME SEBIRE, HELENE VERHELST, JAN DE BLEECKER, \\ BRUNO VAN VLEM, PATRICK VERLOO, AND JULES LEROY
}

\begin{abstract}
Department of Pediatrics, Division of Pediatric Neurology and Metabolism [R.V.C., J.S., E.G., H.V., P.V., J.L.], Department of Neurology [J.D.B.] and Department of Nephrology [B.V.V.], Ghent University Hospital, De Pintelaan, 185, 9000 Gent, Belgium; Department of Pediatrics, Division of Pediatric Neurology and Metabolism [L.D.M.] and Department of Medical Genetics [S.S.], Dutch speaking Free

University of Brussels, Laarbeeklaan, 101, 1090 Brussels, Belgium; Department of Pediatrics, Division of Metabolism [J.V.H.], Leuven University Hospital, 3000 Leuven, Belgium; Department of Pediatrics, Division of Pediatric Neurology [G.S.], Cliniques Universitaires Saint-Luc, 1200 Brussels, Belgium
\end{abstract}

\begin{abstract}
Catalytic activity of oxidative phosphorylation complexes is maintained following separation by Blue Native polyacrylamide gel electrophoresis (BN-PAGE). In BN-PAGE gels, using histochemical staining methods, we have demonstrated enzymatic activity of the complexes I, II, IV, and V in heart and skeletal muscle, liver, and cultured skin fibroblasts. The combination of BN-PAGE and catalytic staining can be successfully applied for detection of complex deficiencies. Tissues from 18 patients with deficiency in the oxidative phosphorylation as detected by spectrophotometric assay were used (10 patients complex IV, three patients complex I, one patient complex II, one patient complex I+III, three patients complex I+IV). The gene defect was located in nuclear DNA in five patients and mitochondrial DNA in one patient. In samples from patients with a severe deficiency, almost complete absence of the corresponding enzyme band is observed after catalytic staining in the gel. In patients with known partial deficiency, a milder decrease of the corresponding enzyme band is demonstrated. The amount of protein in com-
\end{abstract}

\section{ABSTRACT}

plexes I, V, and III can easily be evaluated in samples from heart and skeletal muscle after separation by BN-PAGE using silver or Coomassie staining. The protein amount in complex IV is difficult to visualize by silver staining but easier by the Coomassie technique. In samples from liver and cultured skin fibroblasts, evaluation of protein amount is more difficult due to high background staining. In these tissues, immunoblotting can be done after BN-PAGE and subsequent transfer to a nitrocellulose membrane. (Pediatr Res 50: 658-665, 2001)

Abbreviations
BN-PAGE, blue native polyacrylamide gel electrophoresis
OXPHOS, oxidative phosphorylation
TEMED, tetramethylethylenediamine
NADH, dihydronicotinamide adenine dinucleotide
CoQ, Coenzyme Q
EDTA, ethylenediaminetetraacetate
PMSF, phenylmethylsulfonyl fluoride

The molecular study of oxidative phosphorylation has been aided considerably by the introduction of Blue Native polyacrylamide gel electrophoresis (BN-PAGE), which separates the mitochondrial multiprotein complexes. This progress is due in part to the introduction of the dye Serva Blue G inducing a charge shift on the constituent proteins and in part to the introduction of aminocaproic acid improving solubilization of

Received September 28, 2000; accepted June 19, 2001.

Correspondence: Rudy N. A. Van Coster, Ghent University Hospital, De Pintelaan, 185, 9000 Ghent, Belgium, e-mail: rudy.vancoster@rug.ac.be

Supported by a grant from Fund for Scientific Research (FWO) (contract grant number 31507296) (Rudy Van Coster) and by a grant from 'Kid-Au-Quai' (Caroline Callens Foundation). membrane proteins (1). Under these conditions first dimension electrophoretic separation of the oxidative phosphorylation complexes maintains catalytic activity even after extraction from preparative gels. Using a combination of BN-PAGE and histochemical staining methods, Zerbetto et al. visually demonstrated adequate enzymatic activity of the complexes I, II, IV, and V in control samples of heart and skeletal muscle (2). Moreover, by applying the combined techniques they demonstrated deficient complex I activity in two patients.

By introducing modifications of the methods we have demonstrated enzymatic activity not only in control samples of heart and skeletal muscle but also in other tissues. Besides deficiency of complex I, we detected deficient activity in other 
complexes of the oxidative phosphorylation. The main purpose of this paper is to report these data and discuss their significance in the diagnostic approach to disorders of oxidative phosphorylation.

\section{METHODS}

\section{Tissues and patients}

The tissues, kept at $-80^{\circ} \mathrm{C}$ until studied, were from patients who had undergone diagnostic enzymatic studies and were found to have a deficiency in a single oxidative phosphorylation complex (I, II, or IV), or a combined deficiency as detected by spectrophotometric assay. Biopsies were taken after receipt of informed consent and approval by the Institutional Review Board.

The patients, their clinical syndromes and, when available, the causal mutations are listed in Table 1 according to complex deficiency. The mitochondrial enzyme activities in the different tissues available are tabulated in Table 2. Control tissues were from children and adults deceased from unrelated disorders. Significant differences in activities of the oxidative phosphorylation complexes have not been reported in the various age groups (infants, children, adolescents, and adults) (3).

\section{Chemicals}

Serva Blue $G$ was purchased from Boehringer Ingelheim (Heidelberg, Germany), Coomassie Briljant Blue G 250 from Sigma Chemical Co.-Aldrich (Bornem, Belgium), acrylamide, bisacrylamide, TEMED, ammoniumpersulphate from Bio-Rad (Brussels, Belgium), and the remaining chemicals from Sigma Chemical Co.-Aldrich (Bornem, Belgium). The silver staining kit and Bradford reagents were purchased from Pierce (Antwerp, Belgium).

\section{Spectrophotometric assays}

Spectrophotometric assays previously described were used to measure NADH-CoQ reductase (4), succinate dehydrogenase (5), cytochrome $c$ oxidase (6), and citrate synthase (7). Either whole tissue homogenates or isolated mitochondria were used. Protein concentrations were in the range of $3-5 \mathrm{mg} / \mathrm{mL}$ in muscle homogenates, $2-4 \mathrm{mg} / \mathrm{mL}$ in fibroblasts, and $4-10 \mathrm{mg} / \mathrm{mL}$ in liver. Protein concentration of isolated mitochondria varied between 1 and $3 \mathrm{mg} / \mathrm{mL}$.

\section{Preparation of cultured fibroblasts}

Three $\mathrm{T}_{75}$ flask monolayer cultures of each patient cell strain were used. The monolayers were washed twice at room temperature with a $\mathrm{pH} 7.4$ buffer containing $3.5 \mathrm{mM}$ Tris- $\mathrm{HCl}$, $140 \mathrm{mM} \mathrm{NaCl}$. They were subsequently incubated for $5 \mathrm{~min}$ in this buffer after the addition of $0.02 \%$ EDTA. After this treatment, cells were removed by scraping and transferred to a centrifuge tube. After three consecutive washings with the former washing buffer, the resulting cell pellet was ready for investigation.

\section{Isolation of mitochondria}

Mitochondria were isolated according to the method described by Scholte (8). Either skeletal muscle (50mg), heart muscle $\left(30 \mathrm{mg}\right.$ ), liver tissue $\left(50 \mathrm{mg}\right.$ ), or fibroblasts (three $T_{75}$ flasks) was used. Twenty volumes of buffer $(10 \mathrm{mM}$ Tris- $\mathrm{HCl}$, $0.25 \mathrm{M}$ sucrose, $2 \mathrm{mM}$ EDTA, $50 \mathrm{U} / \mathrm{mL}$ heparin, $\mathrm{pH}$ 7.4) were added to one volume of tissue sample or cultured skin fibroblasts for homogenization in a glass/glass pestle. The homogenate was then centrifuged $(5,600 \mathrm{~g})$ for $1 \mathrm{~min}$. The supernatant was kept on ice. The pellet was resuspended, homogenized, and centrifuged again, as described above. The combined

Table 1. Patients, clinical syndromes, and gene defects listed according to Complex deficiency

\begin{tabular}{|c|c|c|}
\hline Patient initials & Clinical presentation & Gene defect \\
\hline \multicolumn{3}{|l|}{ Complex IV deficiency } \\
\hline N.N. & Neonatal onset, fatal at D4 & \\
\hline B.T. & Early infantile encephalo-cardiomyopathy, fatal at $5 \mathrm{wk}$ & $\mathrm{SCO} 2(11)$ \\
\hline D.A.A. & Early infantile encephalopathy, fatal at $5 \mathrm{~m}$ & \\
\hline D.L.* & Leigh syndrome & SURF-1 \\
\hline D.A.* & Leigh syndrome & SURF-1 \\
\hline J.H.A. & Leigh syndrome & \\
\hline L.T. & Adult myopathy & \\
\hline \multicolumn{3}{|l|}{ Complex I deficiency } \\
\hline M.G. & Neonatal onset, fatal at $24 \mathrm{~h}$ & \\
\hline D.R.C.* & Cardiomyopathy & \\
\hline D.R.L.* & Cardiomyopathy & \\
\hline \multicolumn{3}{|c|}{ Complex I + IV deficiency } \\
\hline D.J. & Leigh syndrome, cardiomyopathy & \\
\hline H.D. & Recurrent rhabdomyolysis from age $22 \mathrm{y}$ & \\
\hline C.J.P. & Muscle wasting, muscle cramps & $\begin{array}{l}\text { Mitochondrial tRNA }{ }^{\text {Lys }} \\
\text { (A8344G MERRF mutation) }\end{array}$ \\
\hline
\end{tabular}

* Patients D.L. and D.A. and patients D.R.C. and D.R.L. are siblings. 
Table 2.

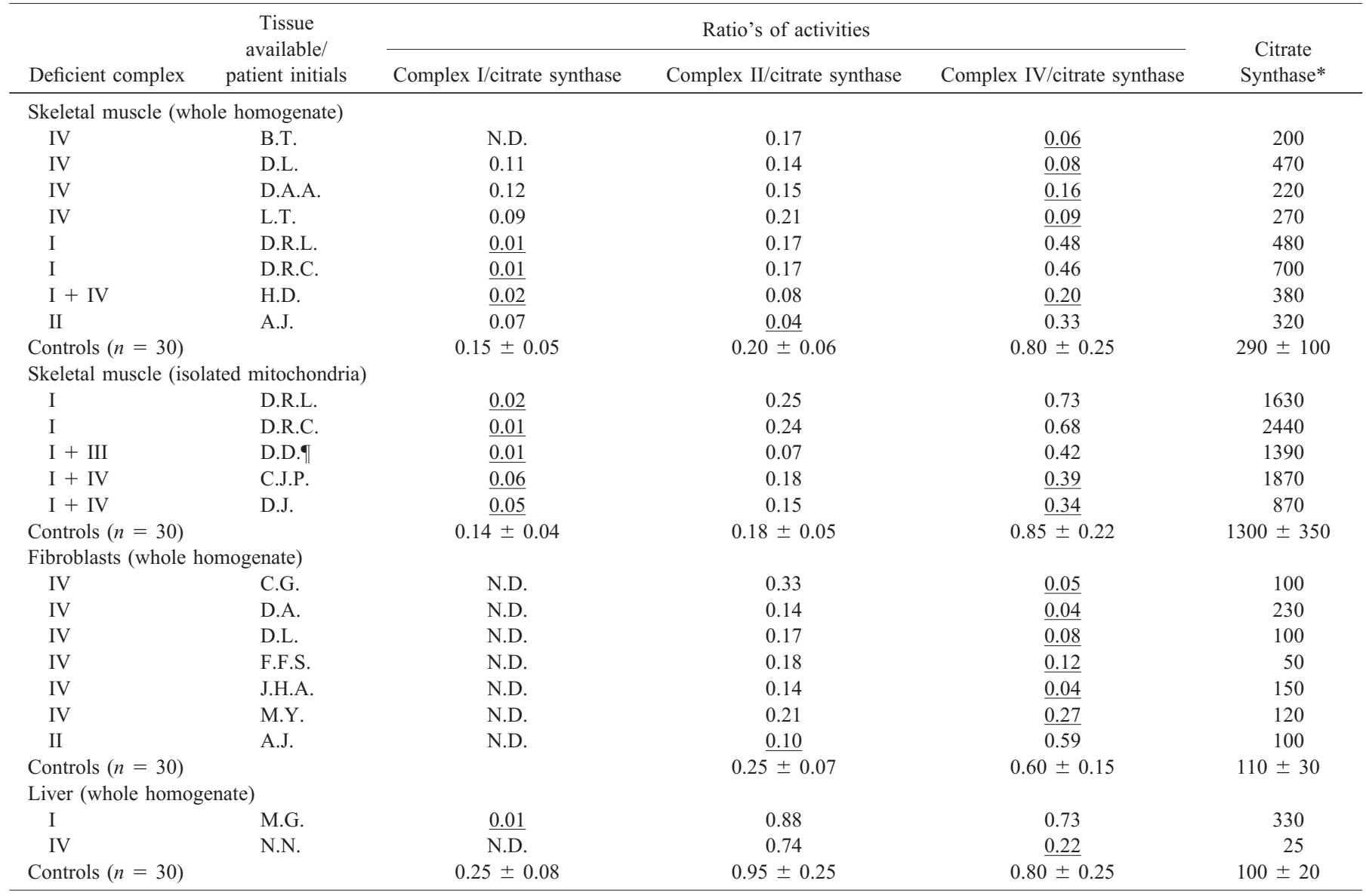

N.D.: not determined, ratios's of controls expressed as mean \pm S.D.

* Specific activity expressed as nmole of substrate/min/mg protein, 9 complex III activity in fibroblasts $1.1 \mathrm{U} / \mathrm{U}$ citrate synthase (controls $1.3-2.6$ ).

Values underlined are outside the \pm SD range.

supernatants were centrifuged at $37,500 \mathrm{~g}$ for $3 \mathrm{~min}$. The resulting pellet was resuspended in $19 \mu \mathrm{L}$ homogenization buffer either per mg wet weight of tissue or per $1 \mu \mathrm{L}$ of fibroblast pellet. The resuspended pellet was homogenized once more and centrifuged again at 37,500g during $3 \mathrm{~min}$. The final pellet containing the mitochondria was frozen at $-80^{\circ} \mathrm{C}$. Pellets derived from liver or cultured fibroblasts underwent one additional washing in $500 \mu \mathrm{L}$ of homogenization buffer. The homogenate was centrifuged for $1 \mathrm{~min}$ at $5600 \mathrm{~g}$ and the supernatant recentrifuged $(10,000 \mathrm{~g})$ for $10 \mathrm{~min}$ yielding the final pellet, which contained the mitochondria (around $0.3 \mathrm{mg}$ of protein).

\section{Solubilization of the oxidative phosphorylation complexes}

The solubilization of the complexes was performed according to a modified protocol of Schägger et al. (1). The mitochondrial pellet was resuspended in $48 \mu \mathrm{L}$ of buffer $(750 \mathrm{mM}$ aminocaproic acid, 50mM Bis-Tris/HCl, $20 \mu \mathrm{M}$ PMSF, pH 7.0) and $6 \mu \mathrm{L} 10 \%$ laurylmaltoside, and the mixture subsequently centrifuged $(100,000 \mathrm{~g})$ for $15 \mathrm{~min}$. The supernatant containing the oxidative phosphorylation enzyme complexes was kept at $-80^{\circ} \mathrm{C}$

\section{Electrophoresis}

Preparation of the polyacrylamide gel. BN-PAGE was performed in a mini-gel apparatus (Miniprotean Bio-Rad). The $6 \%$ to $13 \%$ polyacrylamide gradient, as well as the buffers used for electrophoresis, was prepared as described by Schägger (1).

Preparation of samples. In the samples containing the solubilized oxidative phosphorylation complexes, the protein concentrations were assayed according to Bradford's method (9) and varied between 1.0 and $3.5 \mu \mathrm{g} / \mu \mathrm{L}$. To $50 \mu \mathrm{L}$ of each sample, $2.5 \mu \mathrm{L}$ of a $5 \%$ Serva Blue G solution in $750 \mathrm{mM}$ aminocaproic acid was added before homogenization. The protein load applied to each lane varied between 20 and $70 \mu \mathrm{g}$.

Conditions of electrophoresis. The gels were run at $4-7^{\circ} \mathrm{C}$. Electrophoresis was started at $75 \mathrm{~V}$ until entry of the protein sample into the stacking gel. Before the electrophoresis was continued at 200V for $3 \mathrm{~h}$, the Serva Blue G containing cathode buffer was replaced by a buffer without Serva Blue G.

Protein staining of BN-PAGE gels. Coomassie staining: The gels were incubated for 60 min under constant shaking in the staining solution, a 50/40/10 mixture of distilled water/ methanol/acetic acid and 0.1\% Coomassie Briljant Blue G 250, and subsequently transferred to the destaining solution, a 50/ 40/10 ratio mixture of distilled water/methanol/acetic acid 
until, after approximately $2 \mathrm{~h}$, the bands corresponding to enzyme complexes became readily visible.

Silver staining was performed using the GelCode ${ }^{\circledR}$ SilverSNAP ${ }^{\mathrm{TM}}$ Kit containing staining, developer, and enhancing solutions. The gels were fixed in a 40/10/50 mixture of ethanol/acetic acid/distilled water and washed twice in $10 \%$ ethanol and twice in distilled water. Each washing lasting 5 $\min$. The gels were subsequently stained in a 50/1 mixture of staining/enhancing solutions during $30 \mathrm{~min}$, rinsed for $1 \mathrm{~min}$ in distilled water, and transferred to a 50/1 mixture of developer and enhancing solution for 2 to $5 \mathrm{~min}$. These processes occurred until the electrophoretic protein bands were adequately visible when development was arrested in 5\% acetic acid.

Catalytic staining reactions. For each patient two lanes (each on a different gel) were used for catalytic staining of four complexes. BN-PAGE gels were horizontally divided in two parts, the cutting line situated just below the band of complex III (Fig. 2). The upper part of the first gel was used for complex I staining, the lower part for complex IV staining. The upper part of the second gel was used for complex V staining, the lower part for complex II. Staining solutions and methods were identical to those described previously (2). All staining solutions were aliquoted in 3-4 $\mathrm{mL}$ volumes and kept at $-80^{\circ} \mathrm{C}$. Complex I activity was evaluated after incubation with a solution containing $0.1 \mathrm{mg} / \mathrm{mL} \mathrm{NADH}, 2 \mathrm{mM}$ Tris/HCl, and $2.5 \mathrm{mg} / \mathrm{mL}$ Nitro Blue tetrazolium chloride, $\mathrm{pH}$ 7.4. Complex II activity was evaluated after incubation in a medium containing 4.5mM EDTA, $10 \mathrm{mM} \mathrm{KCN}, 0.2 \mathrm{mM}$ phenazine methosulfate, $84 \mathrm{mM}$ sodium succinate, $10 \mathrm{mM}$ Nitro Blue tetrazolium chloride, in $1.5 \mathrm{mM}$ phosphate buffer $\mathrm{pH}$ 7.4. Complex IV staining was achieved after incubation in $9 \mathrm{~mL} 50 \mathrm{mM}$ phosphate buffer $\mathrm{pH}$ 7.4, containing $5 \mathrm{mg} \mathrm{3,3'-diaminobenzidine,} 1 \mathrm{~mL}$ catalase $(20 \mu \mathrm{g} / \mathrm{mL}), 10 \mathrm{mg}$ cytochrome $c$, and $750 \mathrm{mg}$ sucrose. Complex $\mathrm{V}$ activity was evaluated by incubating the gels in $34 \mathrm{mM}$ Tris, $270 \mathrm{mM}$ glycine, $14 \mathrm{mM} \mathrm{MgSO}_{4}, 0.2 \% \mathrm{~Pb}\left(\mathrm{NO}_{3}\right)_{2}$, and $8 \mathrm{mM}$ ATP, $\mathrm{pH}$ 7.8. The gel lanes were incubated during 3-4 $\mathrm{h}$ in their respective buffer solutions at $37^{\circ} \mathrm{C}$. Thereafter, the gels were fixed for $15 \mathrm{~min}$ in $50 \%$ methanol and $10 \%$ acetic acid, except the gels stained for complex $\mathrm{V}$, which were rinsed

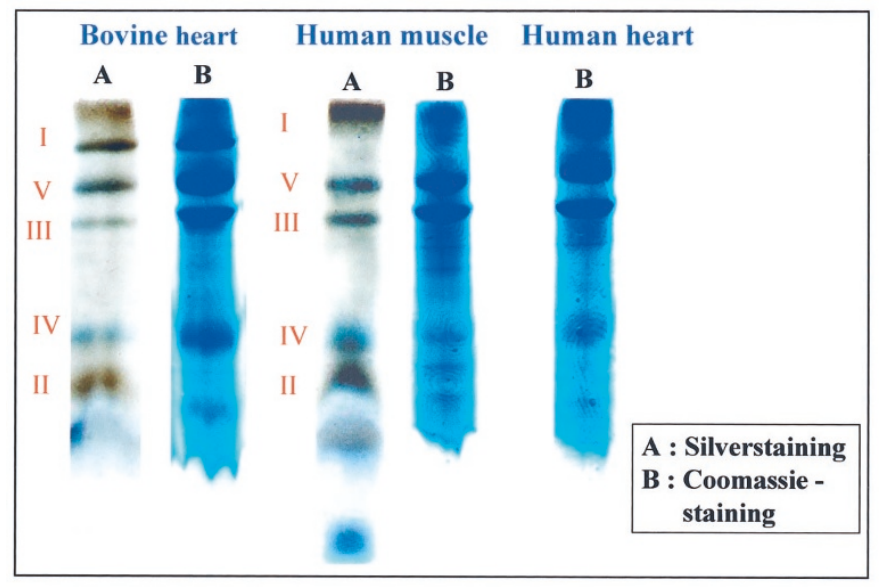

Figure 1. Protein staining of the respiratory complexes in bovine heart, human muscle, and human heart using either silver staining or Coomassie staining. with distilled water. Finally, the gels were packed in a membrane (Gelbond ${ }^{\circledR}$, Sigma Chemical Co.) and scanned using a Sharp JX-330 scanner.

\section{RESULTS}

The results of protein staining of the oxidative phosphorylation complexes in bovine heart, human heart, and skeletal muscle after BN-PAGE and using the silver and Coomassie dye method are shown in Fig. 1. Bovine complex I migrated to a lower position than the human complex I. Complex IV is more difficult to visualize by silver than by Coomassie staining. By contrast, complex II proteins can only be adequately visualized after silver staining.

The results in skeletal muscle from patients and controls obtained by catalytic staining after BN-PAGE are shown in Fig. 3. In the upper part of the gel, staining for catalytic activity of complex I resulted in a dark blue/purple band; in the lower part, complex IV activity resulted in a brown band. In controls and in patients, a double band for complex IV could often be seen. The weaker lower band of the doublet probably represents a partially degraded complex IV that is still catalytically active. The two light blue bands in the upper part of the gels situated below the complex I band represent complexes $\mathrm{V}$ and III that were visible due to the presence of the Serva Blue G, the dye that had been added to the samples before loading to the PAGE gel and to the electrophoresis buffer. Almost complete absence of a band corresponding to complex IV staining was seen in four patients (B.T., D.L., D.A.A., and L.T.). Staining for complex I was normal in skeletal muscle from these patients. Absence of complex I staining was observed in the sibs, D.R.L. and D.R.C., in whom completely normal staining for complex IV was demonstrated.

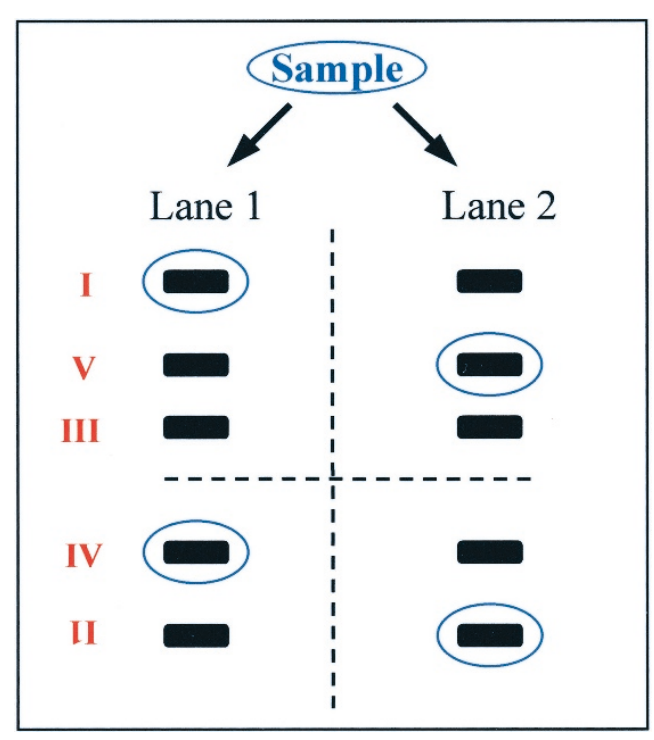

Figure 2. Schematic drawing of the five oxidative phosphorylation complexes separated by the BN-PAGE technique. Two lanes are loaded for each patient. The gels are divided into two parts, shown by the horizontal stippled line. The upper part of the first lane is used for complex I staining, the lower part for complex IV staining. The upper part of the second lane is used for complex V staining, the lower part for complex II staining. 


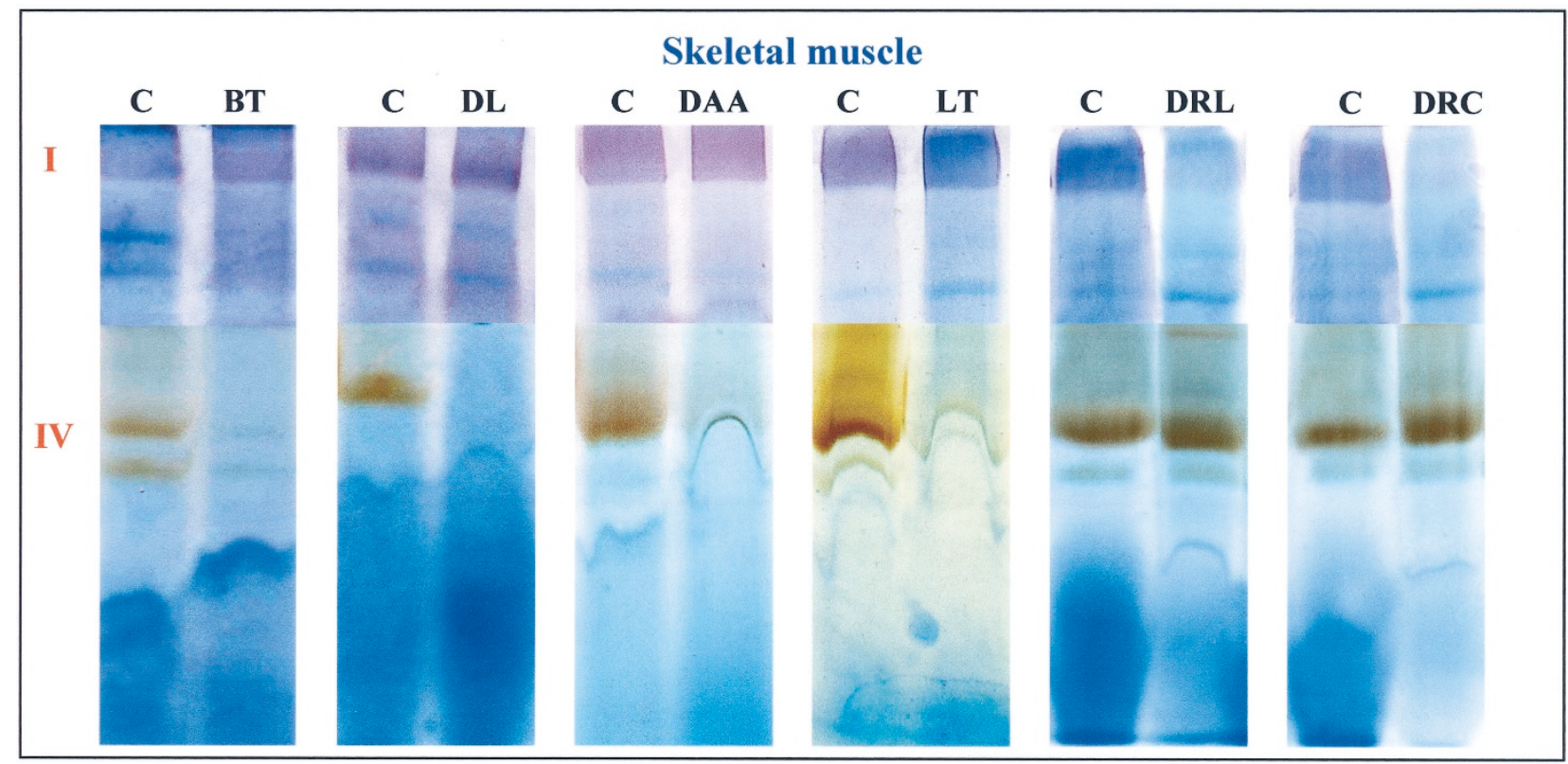

Figure 3. Deficient activity in the complexes IV and I demonstrated by catalytic staining after BN-PAGE in skeletal muscle from patients and controls (C). Examples of isolated complex IV deficiency (Patients B.T., D.L., D.A.A., L.T.) and isolated complex I deficiency (Patients D.R.L. and D.R.C.) are shown. Patients initials at top of gels.

Partial deficiencies were also demonstrated in skeletal muscle (Fig. 5). In a patient (C.J.P.) with an identified MERRF gene defect, a concomitant decrease of catalytic staining for the complexes IV and I was seen, correlating well with the results obtained by spectrophotometric analysis. A combination of complex IV and complex I decrease was also found in a young adult (H.D.) with recurrent rhabdomyolysis, intermittent hyperlactacidemia, and ragged red fibers in skeletal muscle, as well as in a patient (D.J.) with slowly progressive Leigh syndrome (Table 1). In the patient C.J.P., the staining for both complexes I and IV was only slightly less than normal. In the patient H.D., the staining of complex I was severely deficient, while that of complex IV only moderately decreased. In the patient D.J., the decreased staining was more severe for complex IV than for complex I.

Staining for complex V and complex II activity was normal in the patients C.J.P., D.R.L., D.R.C., and D.J. (Fig. 4, left part) and in the patients B.T., D.L., D.A.A., L.T., and D.D. (data not shown). Staining for complex II in patient H.D. showed a rather weak band (data not shown).

The results obtained in cultured skin fibroblasts from controls and patients are shown in Fig. 6. The upper part of one gel

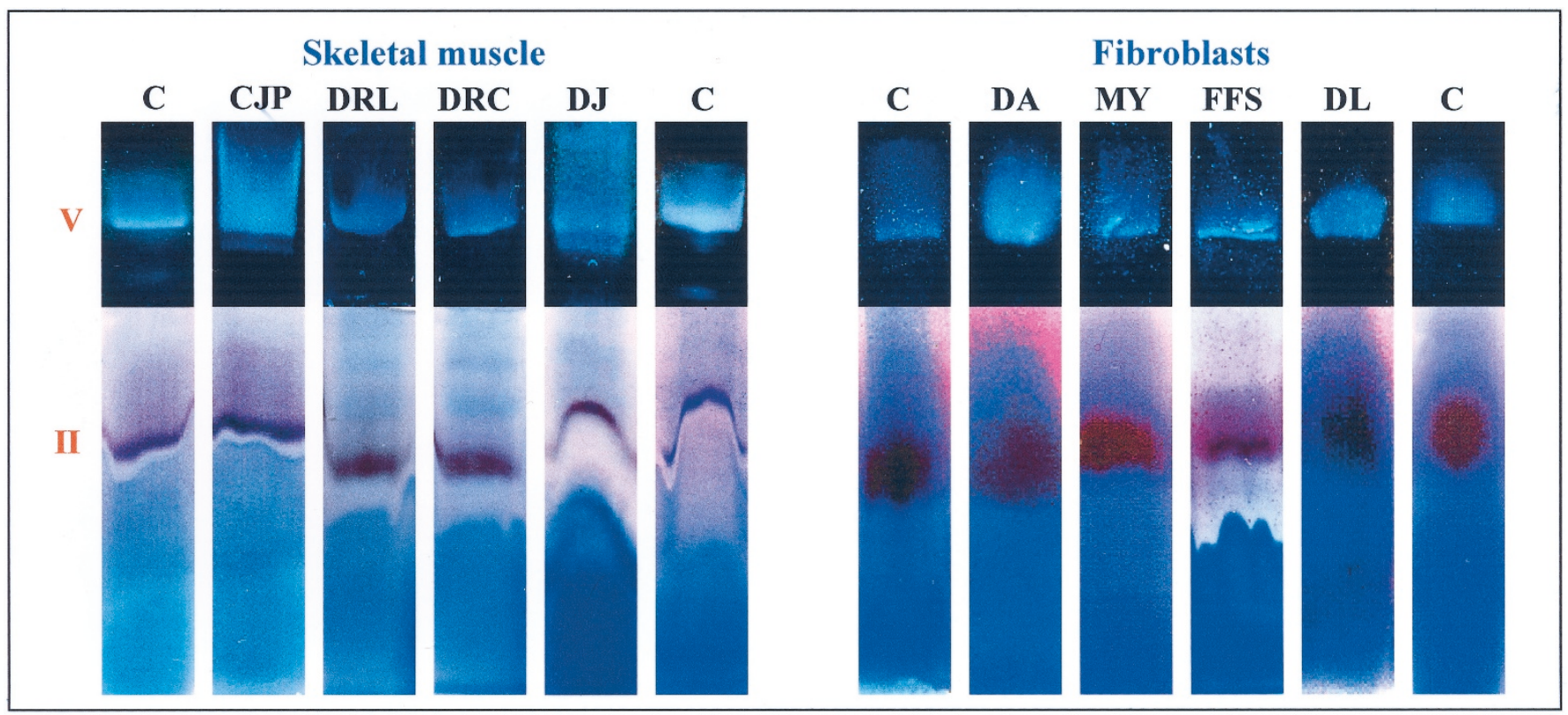

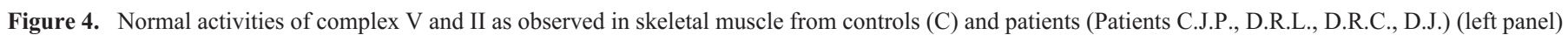
and in fibroblasts from controls (C) and patients (Patients D.A., M.Y., F.F.S., D.L.) (right panel). 


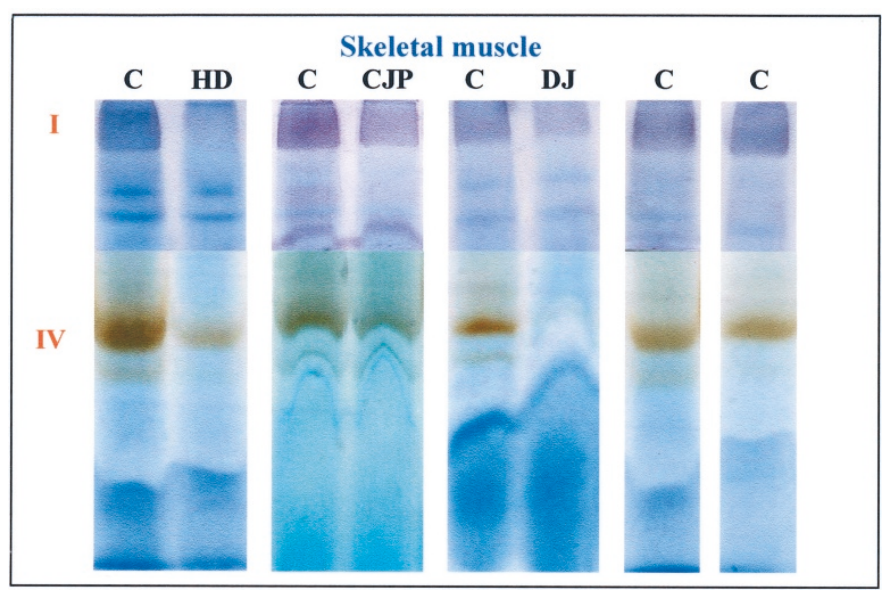

Figure 5. Partial deficiencies of complex I and IV demonstrated by catalytic staining after BN-PAGE in 3 patients and controls (C). In patient H.D., complex I staining is severely decreased but complex IV staining is only moderately decreased. In patient C.J.P., staining for both complexes is slightly decreased. In patient D.J., complex IV is severely decreased, complex I only mildly.

was stained for complex I, the lower for complex IV. Staining of complex IV was almost completely lacking in six patients (D.A., D.L., M.Y., C.G., F.F.S., J.H.A.). Staining for complex I was absent in one patient (D.D.). Cultured skin fibroblasts of only one patient with complex II deficiency (A.J.) were available for BN-PAGE. Complex II activity staining was severely decreased (Fig. 7, left part). In addition, there was an almost complete absence of cross-reacting material in this patient's fibroblasts after transfer of the separated complexes to a nitrocellulose membrane and immunoblotting with a mixture of specific antibodies against the $32 \mathrm{kD}$ and $70 \mathrm{kD}$ subunits in complex II (Fig. 7, right part). In this patient, catalytic staining for complex I and complex IV was normal (data not shown), as was staining for complex V (Fig. 7, left part). Staining in cultured skin fibroblasts for complex $\mathrm{V}$ and complex II was normal in the patients D.A., D.L., F.F.S., and M.Y. (Fig. 4, right part) and in the patients C.G. and J.H.A. (data not shown).

The results obtained in liver tissue from controls and patients are shown in Fig. 8. In one neonate (M.G.), complete lack of complex I staining was demonstrated. In another neonate (N.N.), staining for complex IV was severely decreased (Fig. 8, left part). In either one, staining of the complexes $\mathrm{V}$ and II was normal (data not shown). Activity staining for complex $\mathrm{V}$ and complex II in controls is also shown (Fig. 8, right part). In heart muscle from controls, after staining for complex I, IV, V, and II, corresponding bands could be obtained (data not shown).

Two of the ten patients with isolated complex IV deficiency (D.A. and D.L.) had Leigh syndrome caused by a mutation in SURF-1, an assembly gene (Table 1). A third patient (B.T.) with complex IV deficiency had cardio-encephalomyopathy and was found to have a mutation in the $\mathrm{SCO} 2$ gene, another assembly gene. The fourth patient with complex IV deficiency (N.N.) died in the neonatal period due to overwhelming hyperlactacidemia. The molecular defect in this patient and in the six remaining ones with complex IV deficiency is still to be elucidated.

One of the four patients with known isolated complex I deficiency (M.G.) died in the neonatal period. A complete absence of complex I was demonstrated in his liver, thus providing direct confirmation of the severely deficient catalytic activity detected by the spectrophotometric assay (Table 2). Complex I was normal in his cultured skin fibroblasts, assayed by catalytic staining after BN-PAGE and confirmed spectrophotometrically (measured by Smeitinck, Nijmegen; data not shown). In another patient (D.D.) with complex I deficiency, who had presented with Leigh syndrome, catalytic staining after BN-PAGE was absent in his cultured skin fibroblasts and correlated well with the deficient catalytic activity measured by the spectrophotometric assay (measured by Smeitinck, Nijmegen; data not shown). The sibs (D.R.L. and D.R.C.) with

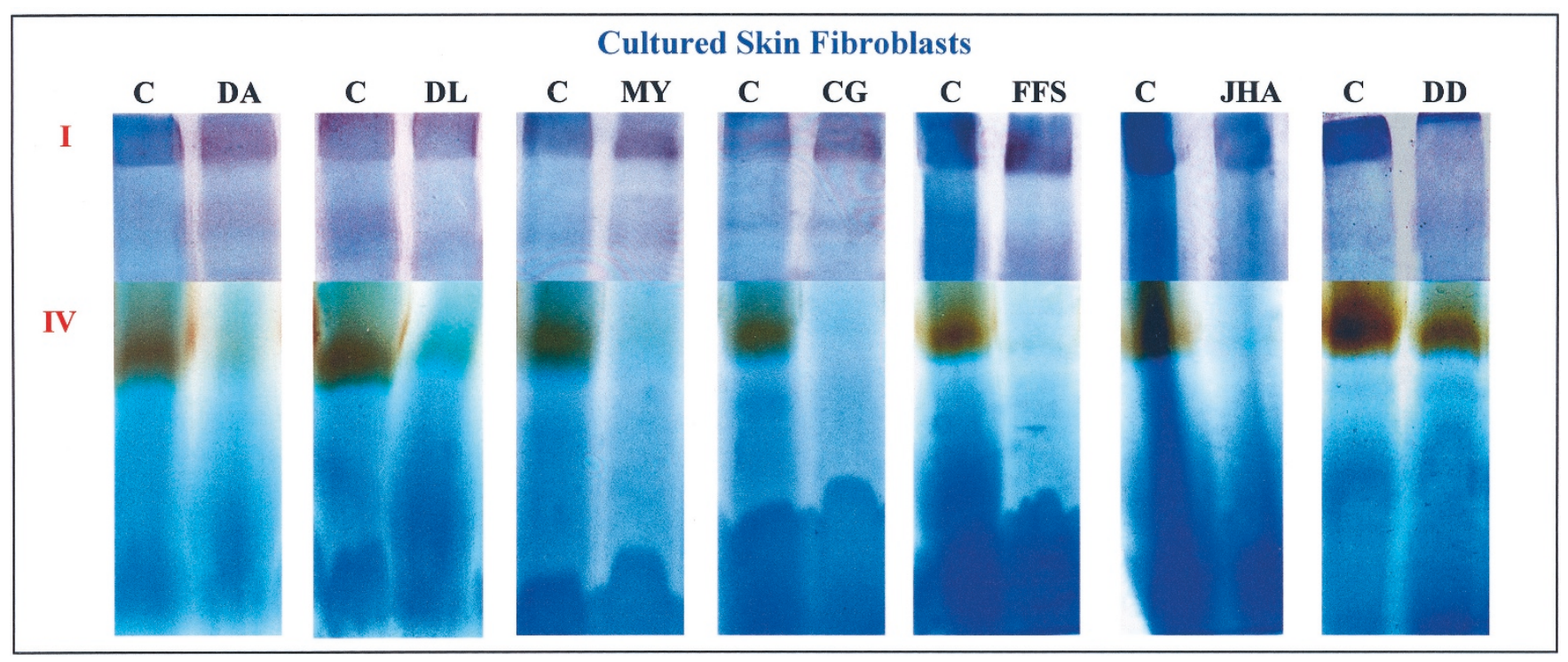

Figure 6. Deficient activity of the complexes IV and I demonstrated in cultured skin fibroblasts by catalytic staining after BN-PAGE. Patients indicated by initials, controls by (C). Isolated complex IV deficiency in patients D.A., D.L., M.Y., C.G., F.F.S., and J.H.A. and an isolated complex I deficiency in patient D.D. are shown. 


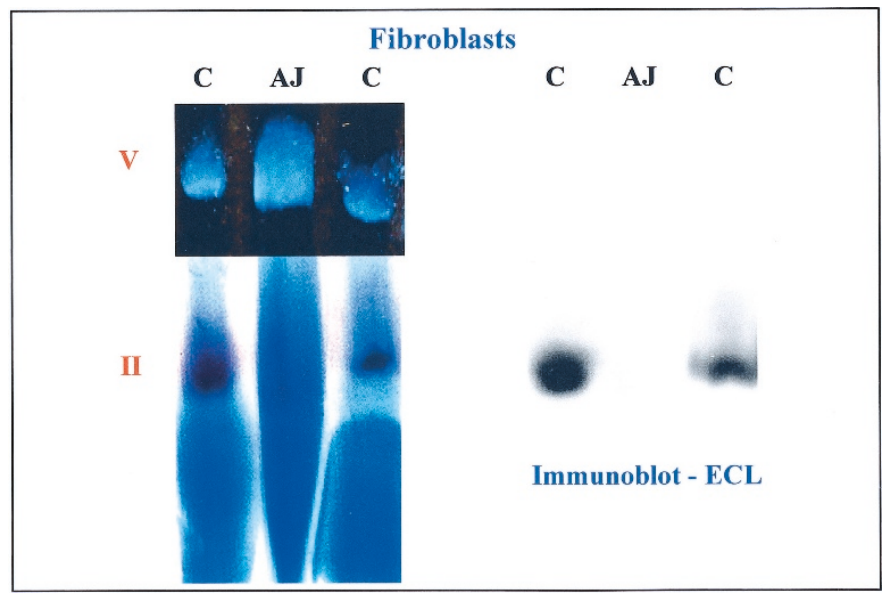

Figure 7. (Left) Deficient catalytic activity of complex II found in one patient cell strain (A.J.). This absence is also demonstrated after transfer to a nitrocellulose membrane and subsequent immunoblotting using combined specific antibodies against the $32 \mathrm{kD}$ and the $70 \mathrm{kD}$ subunit (right).

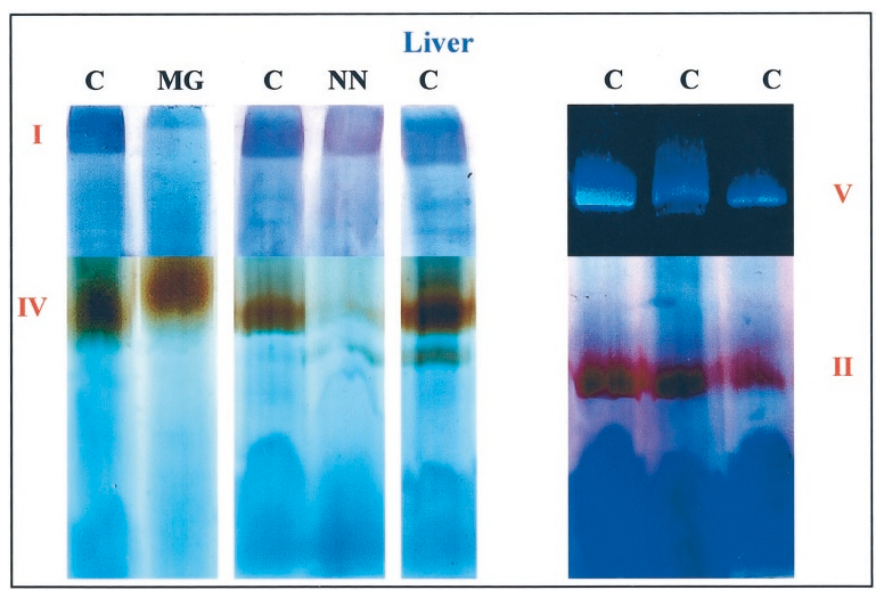

Figure 8. Deficient activity in liver of complex I (patient M.G.) and complex IV (patient N.N.) shown by catalytic staining after BN-PAGE (left). In addition, normal activities of complex V and II in control liver (right).

complex I deficiency detected in their skeletal muscle were afflicted mainly by cardiomyopathy (Table 1).

\section{DISCUSSION}

In this study, we have demonstrated that the technique of BN-PAGE offers important diagnostic possibilities in the patients with oxidative phosphorylation defects. After separation by BN-PAGE, the complexes of the oxidative phosphorylation remain in the native state and thus catalytically active. By applying specific staining reactions originally used for histochemical purposes, Zerbetto et al. showed that in tissue samples from heart and skeletal muscle catalytic activity in complexes I, II, IV, and V can be evaluated in the BN-PAGE gel (2). By introducing modified procedures of sample preparation and altered electrophoretic conditions, we have successfully visualized these catalytic activities not only in heart and skeletal muscle but also in cultured skin fibroblasts and liver.

Zerbetto et al. combined the method of BN-PAGE and catalytic staining for detection in two patients of deficient activity in skeletal muscle complex I. We have extended their findings in tissues from 18 patients by demonstrating that besides complex I deficiency by this method, also catalytic deficiency of complex IV and complex II can be shown visually. In samples from patients with severe, spectrophotometrically documented deficiency, an almost complete absence of the corresponding enzyme band was observed after catalytic staining in the gel. In the few patients with partial deficiency, a more mild decrease of the corresponding enzyme band was found.

An additional major advantage of the combined method of BN-PAGE and catalytic staining is that only relatively small quantities of tissue or cultured skin fibroblasts are required for evaluating the activity in the complexes I, II, IV, and V. Only $30 \mathrm{mg}$ of heart muscle, $50 \mathrm{mg}$ of skeletal muscle, or $50 \mathrm{mg}$ of liver tissue are needed. Three $\mathrm{T}_{75}$ flasks of cultured skin fibroblasts contain sufficient quantity of cells. For the spectrophotometric assay, a three- to four-fold amount of fibroblasts must be available. Especially, measurement of complex I requires large amounts of fibroblasts, the reason being that cultured fibroblasts contain a large amount of nonspecific enzyme activity. Only a small fraction of the latter is rotenonesensitive, precisely the fraction representing complex I activity. An advantage of testing catalytic activity in the BN-PAGE gel precludes colorimetric interference by nonspecific reacting enzymes by running them off the gel. Of importance is also the focusing effect of the electrophoresis technique as it concentrates the activity of a particular complex in one band in the gel. The latter two reasons may explain the success of catalytic staining after BN-PAGE.

That protein concentration in the complexes can be evaluated in the gel represents another advantage of the BN-PAGE technique. For this purpose, an additional lane in a separate gel is loaded with sample. Silver or Coomassie staining is used instead of catalytic staining. The amount of protein in the complexes I, V, and III is often sufficiently high for the representative bands to become visible immediately after separation by BN-PAGE and certainly before any silver or Coomassie staining has been applied, because of the presence of Serva Blue G. The amount of protein in complex IV and complex II is much smaller, with the effect that these complexes are harder to visualize by protein staining. Complex IV is difficult to demonstrate by silver staining but easier by the Coomassie technique. However, the resolving power of the protein staining reactions depends on the tissue studied. In skeletal and heart muscle, background staining is low because there are only a few co-migrating proteins. In liver and fibroblasts, on the other hand, background staining is high. Hence, resolving the proteins in all oxidative phosphorylation complexes is more difficult. Independent assessment of protein abundance in the complexes may be achieved by immunoblotting after BN-PAGE separation and subsequent transfer to a nitrocellulose membrane. To this end, specific antibodies raised against one or more of the major subunits in the complex under investigation may be used. The latter procedure has been successfully applied here to demonstrate visually the severely decreased amount of protein in complex II in cultured skin 
fibroblasts derived from the proband with deficient complex II activity.

Following one-dimensional BN-PAGE, a second electrophoresis (SDS-PAGE) can be applied to obtain, as described by Schägger and von Jagow, separation of the individual subunits in each complex (1). An abundance of subunits may be visualized by protein staining or by immunoblotting using specific antibodies. The subunit profile of a complex may be abnormal in a patient with deficiency of the complex involved. Different mutations may affect a single mitochondrial enzyme complex, but may be associated with different subunit profiles. Recently, distinct patterns of both fully and partially assembled complexes were reported in patients with cytochrome $c$ oxidase deficiency and SURF-1 mutation (10). In this regard, analysis of subunit peptides by tandem mass spectrometry is also a very promising technique.

The major disadvantage of the techniques described is that the results are of a semi-quantitative nature only. However, combining the use of an internal standard with automated densitometry is bound to considerably increase their sensitivity. As an example of internal standard, a bovine heart sample may be proposed, aliquoted, and frozen at $-80^{\circ} \mathrm{C}$ containing a fixed amount of mitochondria, expressed as units citrate synthase.

The method presented here will not be used to replace the spectrophotometric assays but provides a valuable additional tool of investigation. Also, histochemical colorimetric reactions directly applied to tissues remain of utmost importance in diseases because of mtDNA mutations, as they allow the evaluation of catalytic activity in individual cells. Most of the mtDNA mutations are heteroplasmic. Hence, the corresponding encoded catalytic activities of complex I, III, and IV may vary significantly from cell to cell.

We conclude that BN-PAGE combined either with catalytic staining of the individual complexes within the gel, or with protein staining or immunoblotting after transfer to a nitrocellulose membrane, is bound to become a powerful tool in the diagnosis of disorders of oxidative phosphorylation, as it is applicable to various tissue samples. The power of the method also resides in its potential toward two-dimensional extension to resolve and quantify individual complexes into their respective subunits.

Acknowledgments. The authors express their appreciation to Christine Malfeyt for secretarial assistance.

\section{REFERENCES}

1. Schägger H, von Jagow G 1991 Blue native electrophoresis for isolation of membrane protein complexes in enzymatically active form. Anal Biochem 199:223-231

2. Zerbetto E, Vergani L, Dabbeni-Sala F 1997 Quantification of muscle mitochondrial oxidative phosphorylation enzymes via histochemical staining of blue native polyacrylamide gels. Electrophoresis 18:2059-2064

3. Chretien D, Rustin P, Bourgeron T, Rötig A, Saudubray JM, Munnich A 1994 Reference charts for respiratory chain activities in human tissues. Clin Chim Acta 228:53-70

4. Fisher JC, Ruitenbeek W, Gabreëls FJM, Janssen AJM, Renier WO, Sengers RCA, Stadhouders AM, ter Laak HJ, Trijbels JMF, Veerkamp JH 1986 A mitochondrial encephalomyopathy: the first case with an established defect at the level of coenzyme Q. Eur J Pediatr 144:441-444

5. King TE 1967 Preparation of succinate dehydrogenase and reconstruction of succinate oxidase. Methods Enzymol 10:322-331

6. DiMauro S, Servidei S, Zeviani M, DiRocco M, DeVivo DC, DiDonato S, Uziel G, Berry K, Hoganson G, Johnsen SD, Johnson PC 1987 Cytochrome c oxidase deficiency in Leigh syndrome. Ann Neurol 22:498-506

7. Srere PA 1969 Citrate synthase. Methods Enzymol 13:3-11

8. Scholte HR, Ross JD, Blom W, Boonman AM, van Diggelen OP, Hall CL, Huijmans JG, Luyt-Houwen IE, Kleijer WJ, de Klerk JB, Przyrembel H, Verduin MHM, Verstegen JCM 1992 Assessment of deficiencies of fatty acyl-CoA dehydrogenases in fibroblasts, muscle and liver. J Inherit Metab Dis 15:347-352

9. Bradford MM 1976 A rapid and sensitive method for the quantitation of microgram quantities of protein utilizing the principle of protein-dye binding. Anal Biochem $72: 248-254$

10. Coenen MJ, van den Heuvel LP, Nijtmans LG, Morava E, Marquardt I, Girschick HJ, Trijbels FJ, Grivell LA, Smeitinck JA 1999 SURFEIT-1 gene analysis and twodimensional blue native gel electrophoresis in cytochrome c oxidase deficiency. Biochem Biophys Res Commun 265:339-344

11. Papadopoulou LC, Sue CM, Davidson MM, Tanji K, Nishino I, Sadlock JE, Krishna S, Walker W, Selby J, Glerum DM, Van Coster R, Lyon G, Scalais E, Lebel R, Kaplan P, Shanske S, De Vivo DC, Bonilla E, Hirano M, DiMauro S, Schon EA 1999 Fatal infantile cardioencephalomyopathy with $\mathrm{COX}$ deficiency and mutations in $\mathrm{SCO} 2$, a COX assembly gene. Nat Genet 23:333-337

12. Van Coster R, Smet J, De Meirleir L, Lissens W 2000 Sudden deterioration in a 5-month-old baby with complex II deficiency and homozygous mutation in the 70-kDa flavoprotein gene (Gly555Glu). J Inherit Metab Dis 23(suppl 1):141(abstr)

13. Budde SMS, van den Heuvel LPWJ, Janssen AJ, Smeets RJP, Buskens CAF, De Meirleir L, Van Coster R, Baethmann M, Voit T, Trijbels JMF, Smeitink JAM 2000 Combined enzymatic complex I and III deficiency associated with mutations in the nuclear encoded NDUFS4 gene. Biochem Biophys Res Commun 275:63-68 